\title{
Um ensaio sobre a cegueira: covid-19 e a humanização das ciências da natureza
}

\section{- An essay on the blindness: Covid-19 and the humanization of natural sciences}

Roberto Dalmo Varallo Lima de Oliveira'

Resumo: Quem deverá morrer para que a economia não pare? Se a estatística quantifica e faz uma estimativa para um número de mortos, quem julgará que tal número seja elevado ou baixo? As pessoas? O mercado? Pode a Ciência e Tecnologia nos dar essas respostas? Pode, então, o ensino das Ciências e Tecnologias ser humanizado? O presente ensaio se chama "Um ensaio sobre a Cegueira", mas não se refere à obra de José Saramago - confesso que não teria habilidade para tal feito. Ele é um ensaio sobre as Ciências da Natureza e suas Tecnologias, mas, principalmente sobre o seu ensino - ou sobre as diversas formas de ensinar sobre Ciência e Tecnologia. É um ensaio visceral porque foi escrito de forma datada durante a quarentena de uma pessoa que teve o privilégio de poder escrever um ensaio durante a quarentena. É um ensaio sobre Educação em Direitos Humanos escrito por uma pessoa que acredita na urgência de humanizar as Ciências da Natureza e o seu ensino.

Palavras-chave: Educação em ciências. Educação em direitos humanos. Covid-19.

Abstract: Who should die for the economy doesn't stop? If statistic quantifies and estimates the death numbers, who will judge that this number is high or low? People? The market? Can Science and Technology give us these

1 Licenciado em Química pela Universidade Federal Fluminense, Mestre e Doutor em Ciência, Tecnologia e Educação pelo CEFET-RJ. Professor da Universidade Federal do Paraná (UFPR). Pesquisa a relação entre Educação em Direito Humanos e Educação Científica e Tecnológica, sendo autor de livros e artigos sobre o tema. robertodalmo7@gmail.com 
answers? So, can science and technology teaching be humanized? The present essay is called "Blindness", but it does not refer to the work of José Saramago - I confess that I would not have the skills to do this. It is an essay on the Natural Sciences and their Technologies, but, mainly on their teaching - or on the various forms about the use of Science and Technology. It is a visceral essay because it was written in a dated form during a quarantine by a person who had the privilege of being able to write an essay during a quarantine. It is an essay on Human Rights Education written by a person who believes in the urgent need to humanize Nature Sciences and its teaching.

Keywords: Science education. Human rights education. Covid-19.

Definitivamente, esse texto não falará sobre a obra de José Saramago. Este é um ensaio que fala sobre a cegueira - voluntária ou não - que considera as ciências da natureza neutras, imparciais, distantes de qualquer discussão política, emergente do berço europeu do conhecimento. Esse ensaio fala sobre a cegueira de quem vê o ensino das Ciências da Natureza e suas tecnologias distantes das pessoas, distantes da diversidade existente no mundo, distante de um compromisso com a justiça social.

Hoje, 30 de abril de 2020, em Curitiba-PR, início a escrita desse texto. Já são mais de quarenta dias em casa, com certeza - até já me perdi nas contas. Um número que grita é o número de mortos, pois há mais de cinco mil deles nessa data e sabemos que a tendência é que esse número cresça. Mesmo assim, com esse número gritando em nossos ouvidos, há quem pergunte, de maneira asquerosa: "E daí?". Quando você for ler esse texto, sugiro que vá ao Google ou a qualquer buscador disponível e verifique o número de mortos que essa dita "gripezinha" gerou - talvez eu não esteja mais aqui... Os dados estatísticos, como disse um grande empresário brasileiro, afirmam que o número de vítimas seria baixíssimo. Faço, então, o questionamento: pode a estatística ser a única ciência responsável por esse cálculo? Se a estatística quantifica e faz uma estimativa para um número de mortos, quem julgará que tal número seja elevado ou baixo? As pessoas? O mercado?

Quem deverá morrer ou viver para que a Economia não pare? Essa pergunta não pode, jamais, ofuscar as pessoas que já estavam morrendo antes da ameaça da Economia parar. Há pessoas que, durante a pandemia, sofrem em dobro - seja pela ausência de elementos básicos, como tratamento de água e esgoto, ou seja, pela dificuldade do viver, do ficar em casa, com várias pessoas em um cômodo. Quem poderá usar máscara para proteção sem medo de ser confundido com algum assaltante? 
As Ciências nos fornecem aparatos óticos que permitem interpretar o mundo, uma bela interpretação, diga-se de passagem! Porém, em nome da Ciência, muitas atrocidades ocorreram - mulheres negras do Haiti e Porto Rico foram cobaias em experimentos para testagem da pílula anticoncepcional, por exemplo. Hoje, de maneira não muito diferente, fazem a proposta de que as vacinas sejam testadas em africanos(as). Em que evoluímos? Talvez na capacidade de indignação - mas ainda tenho minhas dúvidas.

Ao longo da história, em nome da ciência, muitos saberes foram apagados e as pessoas ligadas a esses saberes, silenciados(as) e mortos(as). Mia Couto nos diz que

A própria ideia de Ciência que nos parece isenta e acima de toda suspeita é tão exclusivista, que pode ser entendida como uma ideia gulosa. Gulosa e glutona. Engorda não por comer, mas por fazer dieta. E essa dieta consiste em ignorar outras sabedorias, outros sistemas de conhecimento. $(2005$, p. 88$)$

O texto em questão dizia: A ciência engorda com a dieta e nós, pessoas da ciência, muitas vezes não enxergamos o comer. Não percebemos o processo e, ao contrário do que podemos pensar, é fundamental compreendermos o esforço e o processo do empreendimento da Ciência para se tornar hegemônica, a fim de que possamos compreender também a diversidade daquelas e daqueles que a negam como tal.

Em um outro ponto, se não podemos nos enganar com uma falsa ideia de Ciência salvadora e distante de algo podre, também não podemos pensar nos Direitos Humanos como tal. Afinal, em nome dos direitos humanos, quantas pessoas foram mortas no combate contra ditaduras? Quantas pessoas, nesses mesmos combates, tiveram seus corpos mutilados, violentados em prol de demonstração de poder barata? Tudo em nome dos direitos humanos e do Estado democrático de direito. Quantas culturas e suas gramáticas de dignidade humana foram deixadas de lado em proveito de uma tentativa frustrada de universalização?

Pode parecer curioso para ti, afinal, um texto que se propõe a discutir a relação entre educação científica e educação em direitos humanos em tempo de pandemia talvez devesse iniciar exaltando tanto as ciências quanto os direitos humanos. Bom, exaltarei, mas ponderadamente, afinal, nossa formação para o controle e para a busca por certezas contribui para que nos agarremos com forças a tudo que aparentemente possa nos salvar em um momento de dúvidas e incertezas, como o de uma pandemia.

Se as ciências da natureza e os direitos humanos não são exclusivamente salvadores, seus ensinos também não são. Reforçamos a importância de uma educação para a formação de valores, porém, o que era o ensino de "Moral e Cívica" se não uma instrução para a formação de valores durante o 
período da Ditadura militar?

Entretanto, preciso dizer que acredito bastante na ideia de uma educação científica e tecnológica que tenha um papel relevante na formação de pessoas, uma educação que vá além do domínio de conhecimentos científicos/tecnológicos - não que eles não sejam importantes; eles são, mesmo, muito importantes! O conhecimento científico nos capacita a calcular com grande destreza e precisão o número de mortos em uma pandemia e a conhecer perfeitamente modelos de propagação de um vírus para sabermos sobre a forma de evitar o contágio. Porém, sem uma formação científica e tecnológica humanizada, ou seja, que estabeleça um equilíbrio entre o conhecimento científico e a formação de valores humanizados, poderemos cair na tentação das soluções vazias.

Para tentar expressar o que entendo como uma educação científica e tecnológica humanizada a partir das relações entre ciências e direitos humanos, eu poderia utilizar alguma definição sobre direitos humanos e, partir desse ponto. Porém, esse caminho não seria tão interessante, pois, certamente, você já leu/ouviu algo do tipo "Direitos humanos são direitos que devem ser garantidos a todos os seres humanos"

Eu até não me atreveria a discordar, mas não acredito que essa afirmação seja tão linear e simples de ser efetivada, como uma definição retirada do Google - ainda digo mais, se fosse simples, todos seríamos defensores dos direitos humanos, por exemplo. Quando um sujeito diz que "Bandido bom é bandido morto!", não estaria ele defendendo uma percepção de humanidade? Categoricamente, eu digo que sim. E vou além, afirmando que essa percepção de humanidade é EXTREMAMENTE diferente da minha, mas não é por isso que deixará de ser um entendimento sobre humanidade. Então, pensar sobre direitos humanos seria muito mais do que tomar pra si uma definição como "direitos que devem ser garantidos a todos os seres humanos" e segui-la.

Pensar direitos humanos seria refletir em um intenso campo de batalha que envolve a elaboração de um entendimento comum e um sentir comum sobre aquilo que é humanidade e sobre aquilo que é ser humano. Uma batalha que se realiza por meio de aspectos simbólicos e físicos. Uma guerra que está no campo discursivo em cada momento que falamos sobre os acontecimentos políticos, que assistimos à televisão, que sentamos na frente do computador em nossa sala com ar refrigerado e decidimos pensar e nos comunicar sobre o que entendemos por humanidade, bem como sobre os acontecimentos de pessoas que jamais saberão de nossa existência. Uma batalha que também é física quando há pessoas sendo despejadas, torturadas, mortas e desaparecidas. É física quando temos uma sociedade na qual o saneamento básico não está na casa de todos e quando alguns não possuem nem casa para reivindicar o saneamento. É física quando um(a) carcerei- 
ro(a) desumaniza um presidiário(a) atacando-o(a) constantemente e impossibilitando sua recuperação. É física quando o(a) presidiário(a) ataca o(a) carcereiro(a).

É simbólica quando uma mulher se sente impedida de usar uma roupa por medo, mas é física porque a violência é real. E dói. Dói fisicamente e psicologicamente quando ocorre um estupro e as pessoas questionam as roupas da vítima. Dói quando dizem que ela não merece respeito e, por isso, foi violentada. Cada um desses discursos e cada uma dessas ações compartilham um "ideal de humanidade" em suas mentes; seja uma humanidade que só merece ser respeitada se utilizar as roupas adequadas, seja uma humanidade que só merece ser respeitada se age de acordo com os padrões, seja uma humanidade que adquire outro sentido quando a pessoa vítima da violência é conhecida ou parente.

Os direitos humanos legalmente materializados são o resultado de elaborações e reelaborações discursivas e afetivas sobre o que é ser humano e sobre o que é a humanidade, salientando que eles estão em um campo de batalha retroalimentado. É sobre esse campo de batalha que estamos falando e, quando falamos, contribuímos para essa batalha. Quando agimos, contribuímos com essa batalha $\mathrm{E}$, dessa forma, podemos dizer que os direitos humanos transformam os sentidos de humanidade e, por eles, são transformados.

Tudo isso que falei é mediado pelo poder, afinal, nem todas essas bataIhas são justas de serem travadas. Podemos dizer que existem assimetrias de poder históricas e tão entranhadas nas nossas representações de mundo que são necessárias forças bastante poderosas se somando a essa batalha, ressaltando que essas forças poderosas fazem com que discursos e ações reverberem ou se silenciem. Discursos e ações sobre o que é ser humano e sobre o que é humanidade. Esse entendimento nos ajuda a pensar em uma parte da questão, os direitos humanos, mas agora você deve estar pensando: e as ciências?

Podemos pensar a partir de diversos entendimentos de ciência, recrutando a Filosofia, a Sociologia, a Antropologia das ciências... E em uma mesa de bar, (pós-pandemia!) Kuhn, Popper, Feyerabend, Lakatos, Fleck, etc. Muitas discordâncias surgirão, mas, em uma ideia comum - aquela que vai tangenciar a todos e proporcionar um brinde - todos concordariam que a ciência é um produto humano, feito por seres humanos e para seres humanos. Poderíamos então dialogar com o supracitado e pensar sobre conceitos de humanidade, de ser humano ou, até mesmo, o pertinente debate sobre o acesso ao conhecimento científico. Sendo assim, trago novamente Mia Couto que, em seu conto "O Adeus da Sombra", nos proporciona esse entendimento: "Existe, afinal, outra incurável doença: a síndrome da humanodeficiência adquirida. Proliferam as ciências desumanas e os cientistas ocultos. Que posso eu contrafazer?" (2012, p. 146).

Pensar direitos humanos seria uma ciência humana, mas pensar sobre Química, Física, Biologia, seria uma ciência desumana? Penso que é nosso 
dever humanizar as ciências da natureza e seu ensino para que os dados interpretados jamais sejam isolados de uma análise humanizada da sociedade, ressaltando que o fato de as ciências serem feitas por humanos e para humanos não garantem sua humanização. Como já citado, estabelecer cálculos sobre a propagação de um vírus e fazer uma estimativa sobre número de mortos é uma atividade das ciências, mas a interpretação de tais dados não pode desconsiderar as pessoas mortas. Hoje, 2 de maio, $9 \mathrm{~h}$ da manhã, já são 6.412 mortes no Brasil. Não pode ser só um número, pois são pessoas, com histórias que se ligam ou não a nós.

A falta de capacidade de indignação possui, como corresponsável, uma ciência "escolar", seja em nível básico ou superior, desumanizada e que foi constantemente gerida por políticas públicas do descaso e, hoje, é gerida por uma necropolítica, ou seja, valorizamos fórmulas, processos, cálculos, números e somos desestimulados a refletir com/sobre as pessoas envolvidas em tais processos. Apagamos suas histórias, silenciamos suas dores e contribuímos para que, num momento de pandemia como esse que vivemos, muitas pessoas que passaram pelo sistema escolar, obrigatório no Brasil, tenham saído de lá com uma grande incapacidade de entender a situação em que estamos vivendo. Contribuímos para que saiam do sistema escolar sem a menor capacidade de entender que mesmo as pessoas que não são de um grupo de risco estão ligadas a outras pessoas que são.

Minha defesa é a de uma educação científica e tecnológica humanizada, pois, assim como a Ciência, seu ensino também é feito por pessoas que possuem diferentes histórias de vida e interações com o mundo que possibilitam a formação de valores diferentes para questões diferentes. Eu costumo fazer uma analogia com um caleidoscópio, um aparelho óptico formado por um pequeno tubo de papel, plástico ou metal, que possui pequenos fragmentos de vidro colorido ao fundo. Com a incidência da luz pelo lado oposto ao do observador e em um arranjo de espelhos surge, a cada movimento, uma combinação variada de efeitos visuais. Assim como o caleidoscópio, pessoas apresentam configurações diferentes para questões diferentes. Somos fragmentados e mudamos de acordo com nossas interações.

Então, uma pessoa negra que sentiu o racismo pode ser motivada para uma luta contra o racismo, mas talvez essa mesma pessoa não tenha tido interações que oportunizassem uma sensibilização com a causa LGBT. Por outro lado, uma pessoa LGBT não necessariamente viveu situações que possibilitaram reflexões e indignação, por exemplo, com a desigualdade de classe social, ou então para reflexões e indignações sobre o machismo. Em resumo, por mais que tentemos estabelecer rótulos para enquadrar pessoas em caixinhas, elas não existem, levando em consideração de que temos inte- 
rações que muitas vezes ressoam bastante em nossa existência e, em outras vezes, nem tanto. Salienta-se que essas interações proporcionam constantes mudanças e elas precisam nos fazer acreditar na existência de transformações. Uma das funções de uma aula de ciências que eu defendo é a de ela ser um espaço que possibilite transformações, ressignificações de mundo. Isso é humanizar a educação cientifica e tecnológica. A ideia do caleidoscópio é interessante por possibilitar que pensemos sobre as interações diferentes ao longo do tempo e como elas irão gerar diferentes configurações de valores.

Algumas dessas interações são tão fortes que nos possibilitam mudanças significativas, como ressalta a filósofa Adela Cortina (2005), a educação em valores consistiria em criar condições para que determinados valores sejam apreciados. Assim, quando ensinamos ciências, nos preocupamos em criar um espaço para a apreciação de valores como o da solidariedade? A capacidade de nos indignarmos com aquilo que não nos atinge de imediato..., de ampliar aquele entendimento/ sentimento de ligação entre os seres é algo que nos importamos quando ensinamos sobre pilhas e eletrólise? Se não, o que podemos fazer?

É um devaneio seguirmos ensinando fórmulas, processos, modelos, sem a preocupação de construir um espaço de valorização das pessoas e de afirmação de valores, como liberdade, solidariedade, diálogo e respeito. Então, o que se deveria fazer é tentar formar pessoas que, em um momento de pandemia, reflitam para além de seu próprio umbigo. Investir milhares de reais em campanha para informar às pessoas que se elas não são de um grupo de risco, devem se prevenir para não expor aqueles que são, ou seja, milhares de reais em campanhas para falar o óbvio que não é tão óbvio porque nos dedicamos mais a calcular curvas do que a interpretá-las em diálogo com uma visão humanista.

Destaco também que uma educação científica e tecnológica sem um profundo compromisso com o combate às desigualdades amplia o poder daqueles que já o detém. É de grande importância que as pessoas dominem conceitos científicos, porém, sem um simultâneo enfrentamento de assimetrias de poder e desigualdades sociais, elas serão mais sábias, mais graduadas, mas continuarão sem ocupar espaços de poder e, se ocuparem, sem serem reconhecidas. Um exemplo? Imagine-se deitado em um hospital e uma moça negra vestida de branco começa a falar com você. Era a [...] do hospital e que estaria responsável pelo seu tratamento. Bom, se você completou [...] com enfermeira e não com médica, pense sobre os motivos disso. Existe sim um racismo estrutural e ou somos corresponsáveis por ele, ou somos aqueles que são oprimidos, mortos e esquecidos.

A educação científica e tecnológica, além de possibilitar que as pessoas se apropriem de conhecimentos clássicos, pelo ponto de vista dos colonizadores, deve possibilitar que os compreendamos também como uma 
ferramenta de legitimação de poder entre culturas e pessoas. Possibilitar esse entendimento não é tocar a bola para terraplanista chutar, ou legitimar que tudo possa ser opinião. Reconhecer a influência de conhecimentos indígenas e quilombolas é um dever com os povos que nos antecederam, além de deixar emergir valores e conhecimentos valiosos.

Eu lembro bem de um dia na escola quando um professor começou a fazer piada com conhecimentos indígenas e quilombolas para demarcar a importância da Química. Também lembro que eu falei para um amigo, no ano seguinte, que o conhecimento dos indígenas era menor e irrelevante. Como essas duas situações se interligam? Tal professor, naquele dia, contribuiu para legitimar que o saber científico era superior em detrimento de outros saberes. Ele reforçou isso com ironias, com piadas. Pensemos que a mesma abordagem poderia ser feita de outra forma, pensemos que essa outra forma contribuiria para que, no ano seguinte, talvez eu tivesse uma outra fala. Hoje, 4 de maio, o Google me informa mais de 7 mil mortes. Duas mil pessoas se foram desde o dia que iniciei esse texto. Quando pensamos apenas em números, as lágrimas não nos tocam, as histórias não nos marcam, porém, quando esse "número" está ao nosso lado, somos capazes de sentir dor. A real dificuldade não está em fazer com que não nos importemos apenas com a morte de uma pessoa próxima, mas construir ambientes que ampliem o nosso entendimento sobre seres humanos, sobre humanidade, ao ponto de nos importarmos com aquilo que não nos atinge diretamente.

Gosto de falar que há muitas formas de construir espaços de relação entre ciências da natureza e direitos humanos, ou seja, espaços de apreciação de valores, de ampliação dos entendimentos sobre humanidade. Em sala de aula, podemos ter abordagens diretas e indiretas. As indiretas ocorrem sem a existência de um planejamento prévio. Ocorrem, por exemplo, no policiamento dos nossos discursos como docentes ou quando professores(as) precisam lidar com situações conflituosas de imediato. Lembram a situação relatada sobre o professor que, para elevar a importância da Química, construiu um discurso contra os saberes oriundos dos povos indígenas e quilombolas?

Uma abordagem indireta consistiria em ele não fazer isso. Policiarmos nossas ações e atos de fala é importante. Imagine um professor que repita rindo a infeliz fala de um cantor que, em um show, comparou os casos de Covid-19 com os casos de pessoas com HIV no Brasil. Estar em sala é um compromisso, assim como escrever. Esse ponto é abordado em Oliveira e Queiroz $(2015$, p. 76$)$ a partir do exemplo de um texto intitulado "O segredo das donas de casa". O texto em questão dizia:

Agora não é preciso usar sal, açúcar, leite ou qualquer outra receita da vovó para tentar retirar manchas difíceis como vinho tinto, café, gema de ovo, refrigerante, entre outras. Temos a química sendo, cada vez mais, útil para as donas de casa e empregadas.

Químicos a cada momento pensam em inovações. Uma delas foi o 
alvejante sem cloro, que solucionou o grande dilema da dona de casa: "será que se eu colocar essa camisa na água sanitária ela vai desbotar?". Quem nunca ouviu a mãe ou a avó falando isso?

Em uma leitura atenta, percebemos indícios de um machismo que poderia não ser reproduzido a partir de simples escolhas que podem ser vistas a seguir:

Agora não é preciso usar sal, açúcar, leite ou qualquer outra receita da vové para tentar retirar manchas difíceis como vinho tinto, café, gema de ovo, refrigerante, entre outras. Temos a química sendo, cada vez mais, útil para as donas de casa empregadas. (para as pessoas).

Químicos(as) a cada momento pensam em inovações. Uma delas foi o alvejante sem cloro, que solucionou o grande dilema: da dona de easa "será que se eu colocar essa camisa na água sanitária ela vai desbotar?". Quem nunca ouviu a mãe ou a avó (alguém) falando isso?...

Nosso discurso e prática servem como referências para muitos(as) estudantes. $O$ segundo exemplo de abordagem indireta ocorre diante da intervenção em situações conflituosas. Em uma aula de Química dos gases, um professor (no caso eu) apresentou a Equação de gases ideais: PV = nRT. Em seguida, um estudante comenta: "Professor, viado não rejeita traveco" - como forma de decorar a equação. Após esse ocorrido, o professor teria duas possibilidades - rir ou problematizar. A resposta foi. "Acho que tem uma inconsistência nessa frase, ser gay não faz com que a pessoa sinta atração por transexuais, a sexualidade é uma coisa, 0 gênero é outra...." Durante o intervalo da aula, um dos estudantes comenta: "nossa, professor, seu comentário tocou meu coração". Outro estudante sentiu-se confortável para relatar uma situação que passava em sua família - um primo morto em um crime movido pela homofobia. Quando estamos em sala de aula, nossas ações/discursos reforçam ou transformam discursos/ações pré-existentes.

Um segundo tipo de abordagem que eu chamo de "direta" consiste basicamente no fato de buscarmos elaborar aulas que deem suporte para a discussão de temas sociais presentes na cultura dos direitos humanos. Nesse caso, podemos destacar a elaboração de sequências didáticas nas quais professores(as) almejem abordar conteúdos conceituais e/ou procedimentais da Química relacionados com conteúdos atitudinais relevantes à cultura dos direitos humanos ou à elaboração de materiais didáticos que dialoguem com atividades lúdicas - como jogos de tabuleiro, videogames, de interpretação, peças de teatro, poesia, entre outros exemplos possíveis.

Tais entendimentos foram citados até agora em um ponto de vista bastante focado no sujeito. Assim, podemos pensar que bastaria aos professores(as) boa vontade e amor pela profissão que estaríamos em um outro patamar. Advirto, no entanto, que esse pensamento é bastante equivocado. Entender que valores, discursos e estratégias para humanizar as ciências da natureza são urgentes e precisam ser trabalhadas intensamente em proces- 
sos formativos para que consigamos construir uma educação científica e tecnológica outra. Dessa forma, NÃO pode ser distanciado de reflexões sobre políticas públicas de educação científica e tecnológica que compreendam a Ciência e Tecnologia como uma produção humana para seres Humanos.

Em 2016, Achille Mbembe publicou um texto intitulado"A era do Humanismo está terminando"2. Para sustentar tal afirmativa, o autor apresentou algumas suposições de futuro que corroborariam sua perspectiva, entre elas: 1) "as desigualdades continuarão a crescer no mundo - mas longe de alimentar um ciclo renovado de lutas de classe -, os conflitos estarão cada vez mais no campo do racismo, sexismo, ultranacionalismo, xenofobia, homofobia, entre outros"; 2) "virtudes como cuidado e compaixão serão cada vez mais difamadas e a crença de que "ganhar é a única coisa que importa" estará cada vez mais cristalizada"; 3) "O apartheid, sob diversas formas, será restaurado e abrirá espaço para impulsos separatistas, construção de mais muros, militarização de fronteiras, formas mortais de policiamento, guerras cada vez mais assimétricas", entre outras.

Assim como ele, temo que o contexto nacional não contribua para que tenhamos esperança de um futuro diferente do apresentado. É possível elencar a ascensão de um conservadorismo violento que, baseado em fake news, busca a militarização das escolas, o cerceamento da liberdade de cátedra, uma assepsia de ideologias não hegemônicas no ambiente escolar, a tentativa de naturalização de violências contra negros e negras, LGBTs, mulheres, povos indígenas, quilombolas, etc. Há uma crescente posição anti-humanista e desprezo pelo conhecimento e pela democracia. Há, assim, um descaso pela ciência, pela pesquisa científica, pelos(as) cientistas e por seus produtos. Entretanto, não podemos nos desesperar e, muito menos, desesperançar, afinal, como diria José Saramago (2016): a cegueira também é viver num mundo onde se tenha acabado a esperança. Assim, quando foco nos sujeitos, é porque acredito nas pessoas e em nossa capacidade de organização e mobilização para pressionar um Estado que faz da necropolítica seu modus operandi. Devemos sim acreditar que fazer pressão é nossa corresponsabilidade como cientistas da natureza: químicos, físicos, biólogos. Não podemos tudo, mas não podemos nos afastar daquilo que está ao nosso alcance.

Dia 5 de maio de 2020, 10 horas e 15 minutos. Encerro esse texto e olho no Google - são 7.367 mortes até agora. São mais de 2 mil pessoas mortas e a irresponsabilidade de um Estado que dirá novamente: "E daí?". Dia 13 de maio de 2020 recebo a última revisão antes do envio. São aproximadamente 12.500 mortes. São 6.500 mortos por Covid-19 desde o início desse texto. São os serviços de academia, salão de beleza, barbearias, podendo ser reabertos por decreto. Afirmar o privilégio não é afirmar a facilidade, mas entender que há mais

2 Disponível em: https://mg.co.za/article/2016-12-22-00-the-age-of-humanism-is-ending/. Acesso em: 13 mai. 2020. 
pedras no caminho de outros(as) que buscarem fazer o mesmo. É o meu privilégio de poder escrever - por ter casa, por ter tido a oportunidade da educação formal, por não dividir essa tarefa com o cuidar de uma criança, por poder simplesmente sentar e escrever. Como disse, não foi fácil. Mas, o que é?

O que nos resta é o enfrentamento e a resistência. É fazer ciência, é entender os motivos pelos quais sua tentativa de hegemonia subalternizou grupos, é entender o porquê de pessoas pensarem que não precisam dela, é atingir a essas pessoas, é mudar, é construir uma outra educação científica e tecnológica - humanizada, combativa -, ter fé no coletivo, acreditar, seguir em frente.

Hoje é hoje, amanhã será amanhã, é hoje que tenho a responsabilidade, não amanhã, se estiver cega, Responsabilidade de quê, A responsabilidade de ter olhos quando os outros os perderam, Não podes guiar nem dar de comer a todos os cegos do mundo, Deveria, Mas não podes, Ajudarei no que estiver ao meu alcance. (SARAMAGO, 2016, p. 267)

\title{
Agradecimentos
}

\begin{abstract}
Agradeço imensamente a cada pessoa que leu previamente esse texto e contribuiu para as discussões: Bárbara Carine Soares Pinheiro, Cristiano Barbosa de Moura, Glória Regina Pessoa Campello Queiroz, José Euzébio Simões Neto, Plábio Marcos Martins Desidério. Camila Silveira da Silva, amiga que compartilhou sua edição impressa do livro de Saramago (com caligrafia de Chico Buarque na capa). Ao amigo João Tenório que zelou pelo "English". Ao companheirismo de Mayra Zakhia.
\end{abstract}

\section{Referências}

CORTINA, A. Cidadãos do mundo: para uma teoria da cidadania. São Paulo: Edições Loyola, 2005.

MBEMBE, Achile. The age of humanism is ending. Mail \& Guardian. Disponível em: https://mg.co.za/article/2016-12-22-00-the-age-of-humanism-is-ending/. Acesso em: 13 mai. 2020.

COUTO, Mia. Pensatempos: textos de opinião. Alfragide/Portugal: Editorial Caminho, 2005.

COUTO, Mia. Estórias abensonhadas. São Paulo. Editora Companhia das Letras, 2012.

OLIVEIRA, Roberto Dalmo V. L.; QUEIROZ, Glória Regina P. C. Olhares sobre a (in)diferença: formar-se professor de ciências a partir de uma perspectiva de Educação em Direitos Humanos. São Paulo. Editora Livraria da Física, 2015.

SARAMAGO, José. Ensaio sobre a cegueira. Lisboa: Porto Editora, 2016. 
